\title{
Currículo e exclusão social: a perspectiva das alunas/professoras do PIBID de Pedagogia
}

Curriculum and social exclusion: the perspective of PIBID Pedagogy students/teachers

\section{Programa escolar y exclusión social: la perspectiva de alumnas/profesoras del PIBID de Pedagogía}

\author{
Ruth Pavan ${ }^{1}$
}

DOI: http://dx.doi.org/10.20435/serie-estudos.v23i49.1161

\begin{abstract}
Resumo: Desde o golpe midiático/jurídico/parlamentar de 2016, a exclusão social tem-se intensificado no Brasil. Ela ocorre por diferentes razões, com destaque para questões políticas, de classe, raça/etnia e gênero. A escola e o seu currículo, marcados pela cultura hegemônica (burguesa, branca, masculina, heterossexual), além de reproduzirem a exclusão da sociedade, produzem também exclusões em seu interior. O artigo pauta-se em um conjunto de autores que têm a preocupação de que, nas escolas e na sociedade, as diferenças não sejam traduzidas em desigualdades. O objetivo é problematizar a concepção das alunas/professoras do Programa Institucional de Bolsas de Iniciação à Docência (PIBID) de Pedagogia sobre os processos de exclusão existentes na escola e na sociedade, relacionando essa concepção com a sua compreensão de currículo escolar. Como instrumento de coleta das informações, foi utilizada a entrevista estruturada. Como resultado, podemos observar que as alunas/professoras percebem diversos processos de exclusão presentes na sociedade e na escola, ou seja, também no currículo escolar.
\end{abstract}

Palavras-chave: currículo; PIBID; exclusão social.

\begin{abstract}
Since the media/juridical/parliamentary coup d'état in 2016, social exclusion has intensified in Brazil. It is due to several reasons, particularly political, class, race/ethnicity and gender issues. The school and its curriculum, marked by the hegemonic culture (which is bourgeois, white, male, heterosexual), besides reproducing social exclusion, have also produced exclusions within themselves. This paper is grounded on a group of authors concerned that differences are not translated into inequalities either in the schools or in society. The objective is to problematize the Institutional Program of Teaching Initiation Scholarship (PIBID) Pedagogy students/teachers' view of exclusion processes in both the school and society, by relating such conception to their understanding of school curriculum. Structured interview was used as an instrument for data collection. As a result, it was possible to notice that the students/teachers perceive a number of exclusion processes both in society and in the school, i.e. also in the school curriculum.
\end{abstract}

Keywords: curriculum; PIBID; social exclusion.

\footnotetext{
${ }^{1}$ Universidade Católica Dom Bosco (UCDB), Campo Grande, Mato Grosso do Sul, Brasil.
} 
Resumen: Desde el golpe mediático/jurídico/parlamentario de 2016, la exclusión social se ha intensificado en Brasil. Esta ocurre por diferentes razones, con destaque en cuestiones políticas, de clase, raza/étnica y género. La escuela y su programa, marcados por la cultura hegemónica (burguesa, blanca, masculina, heterosexual), además de reproducir la exclusión de la sociedad, producen también exclusión en su interior. El artículo se pauta en un conjunto de autores que tienen la preocupación de que, en las escuelas y en la sociedad, las diferencias no sean traducidas en desigualdades. El objetivo es problematizar la concepción de las alumnas/profesoras del Programa Institucional de Becas de Iniciación a la Docencia (PIBID) de Pedagogía sobre los procesos de exclusión existentes en la escuela y en la sociedad, relacionando esa concepción con su comprensión del programa escolar. Como instrumento de recolección de informaciones, fue utilizada la entrevista estructurada. Como resultado, podemos observar que las alumnas/ profesoras perciben diversos procesos de exclusión presentes en la sociedad y en la escuela, o sea, también en el programa escolar.

Palabras clave: programa escolar; PIBID; exclusión social.

\section{INTRODUÇÃO}

Este artigo discute aspectos do currículo e da exclusão social. A exclusão social intensificou-se no Brasil após o golpe midiático/jurídico/parlamentar de 2016. Essa exclusão ocorreu e ocorre por diferentes razões, com destaque para questões políticas, de classe, raça/etnia e gênero. A escola e o seu currículo, marcados pela cultura hegemônica (burguesa, branca, masculina, heterossexual), além de reproduzirem a exclusão na sociedade, produzem também exclusões no interior das escolas em seus currículos. O artigo pauta-se em um conjunto de autores que têm a preocupação de que, nas escolas e na sociedade, as diferenças não sejam traduzidas em desigualdades.

Junto com esses autores, desenvolvemos uma reflexão que se afasta tanto da recorrente redução dos problemas educacionais ao espaço/tempo/escolar, quanto da visão que busca transformar questões marcadamente políticas, culturais, sociais, econômicas e pedagógicas em questões puramente técnicas. Destacamos uma compreensão complexificada dos processos de exclusão presentes na sociedade e no currículo escolar.

Neste artigo, fruto do projeto de pesquisa intitulado "A compreensão dos professores da educação básica sobre os processos de exclusão social atualmente presentes na sociedade brasileira e as relações com as suas concepções curriculares", financiado pelo CNPq e também vinculado ao Programa Institucional de Bolsa de Iniciação à Docência (PIBID/CAPES/UCDB), fizemos um recorte que tem como objetivo problematizar a concepção que alunas do PIDID de Pedagogia que 
estão no início de sua docência, têm dos processos de exclusão existentes na escola e na sociedade. Destaca-se que o PIBID, um "[...] projeto que tem como foco a qualidade e a valorização das práticas escolares, possibilitou a distribuição de bolsas de iniciação à docência a estudantes de licenciaturas, professores de escolas públicas e professores" (FETZNER; SOUZA, 2012, p. 696).

Os sujeitos da pesquisa são acadêmicos do curso de Pedagogia, participantes do PIBID/CAPES de uma universidade localizada na região centro-oeste do Brasil. Como a própria CAPES sugere, os acadêmicos que participam do PIBID/CAPES estão no início de sua docência, motivo pelo qual nos referimos a eles como alunas/professoras². Além disso, metade delas já atuava como professora antes mesmo de participar do PIBID/CAPES. Para identificar o que elas pensam sobre o currículo e a exclusão social, houve uma conversa inicial com elas, e depois foram realizadas as entrevistas.

Em um primeiro momento, faremos uma reflexão sobre o currículo e os processos de exclusão, com o intuito de contextualizar a análise. Em seguida, apresentaremos a análise das respostas das professoras.

\section{CURRÍCULO E A EXCLUSÃO SOCIAL: SITUANDO O LUGAR DA ANÁLISE}

Ao trazermos a discussão sobre as possíveis relações entre o currículo e a exclusão social, lembramos um provérbio africano citado por Torres (2003, p. 81): "é preciso toda uma aldeia para educar uma criança". Ao trazermos esse provérbio, queremos lembrar o quanto o processo educativo é complexo e como a educação escolar de forma alguma está dissociada dos outros espaços educativos da sociedade. Nesse sentido, devemos desconfiar dos discursos educacionais, notadamente vindos da lógica mercadológica, que centram sua análise em uma visão fragmentada de sociedade, negligenciando o fato de que a educação é um fenômeno social, cultural, político e econômico que, como tal, não pode ser pensado fora desses condicionantes. Essa visão fragmentada contribui para responsabilizar a escola e, mais especificamente, os professores pelos problemas em relação aos seus alunos e alunas, quando na verdade esses problemas advêm da sociedade neoliberal, marcada por desigualdade, preconceitos e discriminações, entre outros.

\footnotetext{
${ }^{2}$ Do total de sujeitos da pesquisa, apenas um é do sexo masculino. Subvertendo a lógica machista da língua portuguesa, usaremos sempre o gênero feminino. Além disso, é uma forma que auxilia a preservar o anonimato dos sujeitos.
} 
Diferentemente dessa abordagem fragmentada, simplista e reducionista, entendemos que o processo educativo ocorre no e para o coletivo; portanto, o coletivo é o construtor desse processo: "[...] toda a ação política tem um sentido educativo e [...] toda ação educativa carrega um forte componente político" (GARCIA, 2011, p. 16).

Em relação ao processo educativo, sobretudo o de caráter tecnicista, que olha para a sociedade sempre de forma fragmentada, dificultando a percepção dos problemas em suas diferentes dimensões, é importante enfatizar o que discutem Fetzner e Souza (2012). Segundo as autoras, a perspectiva tecnicista mercadológica aborda os denominados "[...] conhecimentos escolares [...] como únicos e, por meio de únicas linguagens e atividades, [...]" (FETZNER; SOUZA, 2012, p. 687). Elas ainda ressaltam que esse entendimento de conhecimento escolar opera "[...] no sentido da exclusão de outros saberes, experiências e conhecimentos, em geral, das classes populares. Ao excluir esses saberes, a escola exclui também seus portadores" (FETZNER; SOUZA, 2012, p. 687).

Tanto a concepção tecnicista e, portanto, fragmentada de educação, quanto a crítica a essa concepção não são novas no campo da educação e do currículo. Isso não significa que estejam ultrapassadas, pois desconsiderar que a escola faz parte de uma engrenagem maior, isto é, que ela está umbilicalmente ligada à sociedade, desdobra-se em "soluções" que não contribuem para a melhoria educacional, "pelo menos para aqueles que insistem em não aceitar a desarticulação total entre educação e democracia" (LIMA, 2010, p. 14). Como diz o autor, a emancipação não é algo que ocorre sem que a sociedade esteja implicada nesse processo. Os problemas educacionais são reduzidos ao espaço/tempo escolar, mais especificamente aos alunos e professores, tomados como indivíduos dissociados da sociedade. Nesse caso, as escolas, notadamente as públicas, têm sido vistas como ineficientes. Os problemas ficam centrados ou nos professores, acusados de não terem formação, de serem desqualificados e desestimulados, entre outros, ou nos alunos, culpados por serem pobres, sem cultura, com traumas psicológicos por virem de famílias desestruturadas, entre outros. Essa discussão é recorrente, ou melhor, há uma polarização recorrente: o problema está nos docentes ou nos alunos. Essa forma de fragmentar a discussão sobre educação acaba reduzindo o problema a "isso ou aquilo", ao invés de problematizar as questões educativas, levando em consideração as múltiplas dimensões do processo educativo. Inclusive, ignora-se o fato de que 
"[...] a principal força da educação reside, paradoxalmente, na sua fragilidade", ou seja, "[...] nos seus ritmos próprios e geralmente lentos, [...], na incerteza e na falta de resultados imediatos e espetaculares, nos seus continuados processos de diálogo e convivialidade, os quais partem do princípio de que ninguém educa, forma ou muda alguém rapidamente e à força, [...]" (LIMA, 2012, p. 44). Como diz o autor, isso ocorre "[...] porque a educação exige sempre a participação ativa dos sujeitos, ou educandos, no processo educativo" (LIMA, 2012, p. 44).

Podemos afirmar que, entre as múltiplas dimensões do processo educativo, a participação ativa de alunos e alunas e de seus saberes nas práticas escolares têm sido sistematicamente ignorados, conforme já citamos anteriormente com Fetzner e Souza (2012), questão também já exaustivamente problematizada por Freire (2011). Para Candau e Leite (2011, p. 959), "[...] a incorporação de saberes outros que não aqueles tradicionalmente eleitos como legítimos pela escola ainda parece distante das práticas escolares mais usuais". Novamente, trazemos Fetzner e Souza (2012) para questionar: "será que aprender que o racismo, por exemplo, é uma construção histórica decorrente de interesses políticos, econômicos e culturais seria menos importante do que aprender a ler, escrever e calcular?" Essa questão mostra-nos que devemos ficar atentos e fazer uma crítica a um conceito de cidadania que ignora as diferenças e a diversidade cultural, pois, ao ignorá-las, compromete a "[...] reinvenção democrática da cidadania e da emancipação social" (LIMA, 2005, p. 75).

As escolas, inseridas em uma sociedade de tradição burguesa que só reconhece como legítimo o conhecimento que tem suas marcas (eurocêntrica, classe alta/média, branca, masculina, heterossexual), tornam-se espaços de transmissão desse conhecimento, em vez de se constituírem em espaços-tempos de "[...] interculturalidade crítica e criativa, ou seja, encontro de diferentes saberes, lógicas e epistemologias que diferentes sujeitos alunos trazem de suas vivências e histórias de grupo e pessoais" (GARCIA, 2012, p. 105).

Isso nos remete a dois elementos que entendemos como centrais no processo educativo: currículo escolar e processos de exclusão. Ao referirmo-nos ao currículo escolar, estamos considerando que há diferentes currículos em circulação na nossa sociedade. Toda a "aldeia" - no nosso caso, toda a sociedade - educa uma criança. Nesse sentido, como diz Veiga-Neto (2004, p. 53), "[...] continuo me juntando - pelo menos por enquanto... - àqueles que estendem o conceito 
de currículo para fora dos muros escolares, falando em currículo das novelas, currículo das revistas de moda, currículo dos shopping-centers" (grifos do autor). Entretanto, neste artigo, centramo-nos no currículo escolar, com destaque para as questões culturais, pois "[...] o currículo se situa na articulação entre a escola e a cultura" (VEIGA-NETO, 2004, p.53), e "[...] frequentemente a escola converte diferenças culturais em desigualdades" (CANDAU; LEITE, 2011, p. 963).

O currículo nunca é simplesmente uma montagem neutra de conhecimentos, que de alguma forma aparece nos livros e nas salas de aula de um país. Sempre parte de uma tradição seletiva, da seleção feita por alguém, da visão que algum grupo tem do que seja conhecimento legítimo. Ele é produzido pelos conflitos, tensões e compromissos culturais, políticos e econômicos que organizam e desorganizam um povo. (APPLE, 2000, p. 53).

Quanto ao segundo elemento - os processos de exclusão -, reconhecemos que "o outro excluído é uma produção social que se atualiza através de diversas práticas escolares" (ESTEBAN, 2004, p. 165); ele é parte do processo pedagógico.

Santomé, em entrevista a Delboni e Silva (2012), lembra que teve colegas que sofreram nos tempos de escola porque se envergonhavam das suas famílias e odiavam a situação em que se encontravam, mas não receberam nenhum tipo de explicação que os ajudasse a entender por que eram pobres em relação às outras pessoas. Segundo o autor, é importante não só que alunos e alunas entendam o mundo em que vivem, mas que também saibam/aprendam que é possível mudá-lo. Portanto a crítica ao princípio de uma educação competitiva, utilitarista e mercantilista é fundamental, pois ela é,

[...] no limite, um princípio contrário a uma educação humanista e crítica, orientada para a solidariedade e o bem comum, colocando toda a pressão na adaptação individual, na adequação e no ajustamento em termos dos conhecimentos, das qualificações e, agora, das 'competências' que se exigem. A educação é, por esta via, desvinculada de uma cidadania democrática para a emancipação social. A construção da cidadania moderna assentou já, em muitos casos, em hierarquias e desigualdades de classe, de género e de raça, revelando-se incapaz de romper com a tradição imperial e colonial europeia e com a sua missão civilizadora e redentora. Essa perspectiva não só não foi afastada como conhece hoje novas articulações com visões etnocêntricas baseadas em modelos de desenvolvimento e em relações económicas e culturais de dominação, dando lugar a uma cidadania de segunda classe, isto é, mitigada e altamente estratificada. (LIMA, 2005, p. 84). 
Isso significa que a escola não pode ser vista como uma instituição descolada da sociedade. As escolas precisam ser entendidas como "[...] locais econômicos, culturais e sociais que estão inextrincavelmente atrelados às questões de poder e controle" (GIROUX, 1997, p. 162). Portanto o trabalho da escola não é, de forma alguma, neutro e desinteressado, seja em relação aos chamados conteúdos escolares, seja no que tange aos valores veiculados no espaço/tempo escolar: "[...] as escolas são lugares que representam formas de conhecimento, práticas de linguagem, relações e valores sociais que são seleções e exclusões particulares da cultura mais ampla" (GIROUX, 1997, p. 162).

Essas seleções e exclusões têm sistematicamente afetado os sujeitos que não pertencem aos grupos hegemônicos. Em um primeiro momento, o "[...] binômio exclusão-inclusão está vinculado à problemática da desigualdade social, característica estrutural das sociedades capitalistas em que vivemos" (CANDAU, 2009, p. 19). Essa ênfase na desigualdade social continua absolutamente pertinente, porém, ela "[...] não dá conta das diferentes dimensões da problemática da inclusão-exclusão presentes na nossa sociedade. As questões relativas à diferença e às políticas de identidade também estão a elas articuladas" (CANDAU, 2009, p. 19). Portanto, ao pesquisarmos o que pensam as alunas/professoras participantes do PIBID, é importante atentar também para as diferenças e as políticas de identidade, ou seja, analisamos "[...] as escolas e seus currículos como territórios de produção, circulação e consolidação de significados, como espaços privilegiados de concretização da política de identidade" (COSTA, 1999, p. 38).

É importante, tanto para a escola quanto para o seu currículo, "[...] explicitar como têm sido aprendidos os significados das diferenças e das desigualdades que nos apartam uns dos outros e que têm justificado tanta opressão, tanta marginalização, tanta dor" (MOREIRA, 2008, p. 12). Desse modo, ajudaremos a "[...] desenvolver uma política de identidade que contribua para que se desestabilizem tradições consolidadas que definem as pessoas segundo gênero, raça, cultura e nação" (MOREIRA, 2008, p. 12).

Ao entendermos a escola e o currículo dessa forma, estamos reconhecendo que mudá-los não é uma tarefa simples, como dão a entender alguns setores da mídia ou algumas empresas, supostamente interessadas na qualidade da educação. Entender as escolas e os currículos como "[...] um conjunto de práticas indissoluvelmente ligadas às demais práticas sociais, [significa que] pensar qualquer 
mudança no âmbito da escola implica pensar como as coisas estão se passando no âmbito da sociedade" (VEIGA-NETO, 2003, p. 109).

É nessa perspectiva que estamos discutindo neste texto tanto o currículo escolar quanto os processos de exclusão como elementos que atravessam todo o tecido social. Embora alguns processos de exclusão possam parecer específicos do currículo escolar (exemplo: a repetência), também eles têm relação com o tecido social mais amplo, pois se legitimam à medida que a sociedade, de alguma maneira, referenda ações discriminatórias, geralmente escondidas atrás de uma pseudoneutralidade, usando a meritocracia como forma de julgamento das ações escolares.

Portanto entendemos a exclusão como um "[...] processo complexo e multifacetado, uma configuração de dimensões materiais, políticas, relacionais e subjetivas" (SAWAIA, 2009, p. 9). É importante apontar que, na sociedade na qual vivemos, a exclusão não "[...] é uma coisa ou um estado, é processo que envolve o homem [e a mulher] por inteiro e suas relações com os outros. Não tem uma única forma e não é falha do sistema; ao contrário, é produto de seu funcionamento" (SAWAIA, 2009, p. 9). Ou seja, a exclusão é produzida pela sociedade capitalista, e não pelo indivíduo excluído, como a lógica capitalista quer fazer acreditar.

Cabe ao currículo escolar, então, ainda que relacionado ao tecido social da sociedade capitalista, problematizar todas as formas de exclusão existentes na sociedade, bem como as que são (re)produzidas pela própria escola. Sobretudo, cabe-lhe mostrar que não é o indivíduo ou determinados grupos sociais que se excluem, mas a sociedade que produz diferentes processos de exclusão. Assim o currículo escolar poderá contribuir para a dignidade, a emancipação das pessoas e a justiça social. O que as alunas/professoras (iniciantes na docência) pensam sobre isso é o que passaremos a analisar a partir de agora.

\section{CURRÍCULO E EXCLUSÃO SOCIAL: A COMPREENSÃO DAS ALUNAS/ PROFESSORAS}

Em consonância com a perspectiva de currículo e o entendimento de exclusão social apontados anteriormente, destacamos que a metodologia de nossa pesquisa "[...] caracteriza-se pela investigação crítica, de abordagem qualitativa" (SAUL, 2012, p. 43). Significa dizer que nossa análise continuará priorizando as relações sociais presentes na sociedade e que consideramos as alunas/professoras 
pesquisadas como produzidas não só pela sua formação inicial, mas por toda a sociedade, lembrando Álvaro Vieira Pinto (1984), que afirma que quem educa o educador é a sociedade. Nosso campo, como já apontamos na introdução, contemplou professoras (acadêmicas) que participam do Programa Institucional de Bolsa de Iniciação à Docência (PIBID) do curso de Pedagogia de uma universidade particular da região do centro-oeste do país. Participaram da pesquisa oito professoras ${ }^{3}$ de um total de dez. Quatro possuem experiência de docência anterior ao programa, e as denominamos de P-5, P-6, P-7, P-8; quatro estão atuando em sala de aula pela primeira vez, e as denominamos de P-1, P-2, P-3 e P-4.

O procedimento utilizado para recolher os dados referentes a questões sobre compreensão de currículo e exclusão social envolveu primeiramente um diálogo com todas as participantes sobre a pesquisa; em seguida, as alunas/professoras responderam a um questionário com perguntas abertas, com a presença da pesquisadora durante todo o processo.

As alunas/professoras, ao serem questionadas sobre o que significa currículo escolar, responderam: "São as disciplinas exigidas no processo educacional" (P-1); "É o planejamento do caminho que será percorrido durante o tempo que o mesmo procura determinar" (P-2); "O que se pretende trabalhar no decorrer do ano" (P-3); "São as matérias que compõem a grade de determinada turma. São os assuntos que serão abordados em determinado curso ou turma" (P-5); "Seria o que poderia trabalhar na escola em todo aspecto" (P-6); "[...] o trabalhar em sala como o currículo nos pede" (P-7); "Currículo escolar significa as atividades desenvolvidas, tudo o que acontece no ambiente escolar".

Como podemos observar, as alunas/professoras, com exceção de uma, que não respondeu (P-4), concebem o currículo a partir da ideia de planejamento curricular, das disciplinas/matérias e atividades desenvolvidas na escola. As teorias críticas de currículo lembram-nos de que o professor não deve se "[...] preocupar apenas com a organização do conhecimento escolar, nem pode encarar de modo ingênuo e não problemático o conhecimento recebido" (MOREIRA; TADEU, 2011, p. 28). Podemos observar, com base nas respostas que as professoras deram, que elas ainda tratam o conhecimento escolar como algo "dado" e "pronto". Parecem

\footnotetext{
${ }^{3}$ Lembramos que havia só um sujeito do sexo masculino e, para auxiliar no anonimato, usamos somente o gênero feminino. Lembramos ainda que optamos por denominá-las de professoras porque participam do Programa Institucional de Iniciação à Docência.
} 
ignorar o fato de que o conteúdo/conhecimento selecionado para ser transmitido nas escolas deve "[...] ser visto não apenas como implicado na produção de relações assimétricas de poder no interior da escola e da sociedade, mas também como histórica e socialmente contingente" (MOREIRA; TADEU, 2011, p. 28).

Lembramos que o conhecimento trabalhado nas escolas está longe de ser desinteressado. Porém, muitas vezes, os conhecimentos são fixados como únicos e vistos como desinteressados. Entretanto, na verdade, esses conhecimentos produzem determinados efeitos e finalidades (FEZTNER; SOUZA, 2012).

O que chama atenção nas respostas das alunas/professoras é a diferença entre elas e as encontradas em uma pesquisa efetuada por Pavan (2012) com professoras que já tinham concluído sua formação inicial. As professoras que já concluíram sua formação inicial têm uma concepção de currículo semelhante à das alunas/professoras, mas têm muita dificuldade de reconhecer processos de exclusão na sociedade e, principalmente, no currículo escolar. Já as alunas/professoras (iniciantes), apesar de manifestarem uma concepção de currículo que não problematiza nem o conteúdo, nem o que ele faz com os alunos, reconhecem processos de exclusão tanto na sociedade quanto na escola.

No que se refere aos processos de exclusão na sociedade, obtivemos como respostas: "Sim e muito. Isso começa na escola. Ainda a educação é para poucos e de fato excludente e elitista" (P-1); "Sim, por grupos sociais, por exemplo, é determinada uma forma ideal de agir. Os que não se adaptam a este estilo são excluídos. Também muito comum é por determinada pessoa possuir necessidades especiais" (P-2). "Muito. A sociedade exclui o diferente, o incomum, portadores de algum tipo de necessidade especial, afrodescendentes e outros tipos, como visual" (P-3); "Sim, um exemplo é por classe social" (P-4); "Percebo que há exclusões, pois, infelizmente, as pessoas sofrem com as desigualdades, e grande parte da população vive com o mínimo necessário para sobreviver, e às vezes até isso Ihes falta. As pessoas com necessidades especiais são excluídas, pois lhes falta assistência" (P-5); "De uma maneira, a sociedade exclui, talvez pela falta de uma boa educação, da família por perto" (P-6); "Há vários tipos de exclusão na sociedade, como a do preconceito com as raças e as diversidades" (P-7); "Sim, vários. Pelas condições financeiras, por exemplo, pela exclusão da criança" (P-8). Como se pode observar, todas que responderam afirmaram que há processos de exclusão na sociedade. 
Da mesma forma, todas que responderam (P-4 não respondeu) disseram que há exclusão na sala de aula: "Sim, por vários motivos, mas o que me chama muito a atenção é a exclusão pela classe social e etnia." (P-1); "[...] sim, principalmente na questão de grupos sociais" (P-2); "[...] alguns comentários dos adultos [...] faz o olhar simples e sem preconceito da criança se encher de maldade". (P-3); "Percebo que crianças que são avançadas de série pela vontade dos pais e sem nenhum critério acabam não acompanhando a turma" (P- 5); "Acredito que exista; a falta de respeito contribui para a exclusão" (P-6); "O que mais vemos em sala de aula é a exclusão com crianças especiais e com negros" (P-7); "Sim, quando o professor deixa de dar a atenção necessária que a criança precisa, pelo comportamento dela" (P-8).

É importante observarmos, nas respostas acima, que para muitas alunas/ professoras a exclusão na sala de aula não está vinculada a uma forma, mas a várias formas, aproximando-se de uma concepção mais complexificada de exclusão.

Destacamos a resposta da professora P-5, que se referiu às crianças que "[...] acabam não acompanhando a turma". Embora a aprendizagem historicamente tenha sido apontada como fator de exclusão nas escolas, fundamentados nos autores deste artigo, enfatizamos que a não aprendizagem é consequência de uma exclusão anterior. Esteban (2012), embora referindo-se à avaliação em larga escala, traz uma reflexão que serve também para a avaliação que ocorre no interior das escolas. Segundo ela, "ignora-se, na análise desses dados, as experiências das crianças como participantes de uma sociedade marcada, de modo desigual, pela cultura escrita" (ESTEBAN, 2012, p. 582).

\section{CONSIDERAÇÕES FINAIS}

Ao finalizarmos o artigo, em primeiro lugar, queremos registrar que nossa intenção, ao desenvolvermos pesquisas com alunas/professoras no início da docência, não foi efetuar uma análise centrada no indivíduo, como se este fosse o autor de suas concepções. As alunas/professoras são os efeitos dos processos formativos desenvolvidos não só pela formação inicial e continuada, mas por toda a sociedade: é preciso toda uma sociedade para educar a professora e o professor.

Em segundo lugar, queremos retomar duas pesquisas anteriores feitas por nós (PAVAN, 2005; 2012). Na primeira, realizada em 2005, com professores de jovens e adultos, os professores não percebiam exclusão, afirmando que ela não 
existe e que é o indivíduo que se exclui. Na segunda (2012), com professores que já haviam concluído sua formação inicial e estavam inseridos formalmente na profissão docente, a tendência era perceber processos de exclusão na sociedade, mas com dificuldade de reconhecer a exclusão pelo currículo escolar. Finalmente, na pesquisa que originou este artigo, feita com alunas/professoras ainda em formação inicial, constatou-se que elas percebem que há exclusão na sociedade e na escola, apesar de ainda manifestarem uma concepção de currículo restrita às disciplinas e às atividades realizadas. Nesse sentido, reiteramos que os cursos de formação devem promover discussões que incorporem as reflexões das teorias críticas e pós-criticas do currículo.

Mesmo assim, sem querer tirar uma conclusão apressada, parece que a sociedade e a formação inicial estão mudando. Provavelmente, essa mudança está relacionada a uma série de políticas educacionais implementadas por pressão da sociedade civil organizada (política de cotas, PROUNI, inclusão de disciplinas sobre a diversidade na formação inicial, LIBRAS, presença maior da diferença na universidade...). Pode ainda estar relacionada ao PIBID, um programa que articula de forma ímpar a formação docente com a realidade escolar, uma vez que todos os sujeitos da pesquisa realizada pertencem a esse programa.

\section{REFERÊNCIAS}

APPLE, Michael W. Política cultural e educação. São Paulo: Cortez, 2000.

CANDAU, Vera Maria; LEITE, Miriam Soares. Diferença e desigualdade: dilemas docentes no ensino fundamental. Cadernos de Pesquisa, São Paulo, v. 41, n. 144, p. 948-67, set./ dez. 2011.

CANDAU, Vera Maria. Educação e inclusão social: desafios para as práticas pedagógicas. In: CANDAU, Vera Maria (Org.). Didática: questões contemporâneas. Rio de Janeiro: Forma \& Ação, 2009. p. 15-28.

COSTA, Marisa Vorraber. Currículo e política cultural. In: COSTA, Marisa Vorraber (Org.). O currículo nos limiares do contemporâneo. Rio de Janeiro: DP\&A, 1999. p. 37-68.

DELBONI, Tânia Mara; SILVA, Sandra Kretli da. O currículo integrado como campo possível de invenção de mundos plurais e emancipatórios: uma conversa com Jurjo Torres Santomé. Revista Teias, Rio de Janeiro, v. 13, n. 27, p. 279-86, jan./abr. 2012.

ESTEBAN, Maria Teresa. Considerações sobre a política de avaliação da alfabetização: pensando a partir do cotidiano escolar. Revista Brasileira de Educação, Rio de Janeiro, v. 17, n. 51, p. 573-92, set./dez. 2012. 
. Diferença e (des)igualdade no cotidiano escolar. In: MOREIRA, Antonio Flavio; PACHECO, José Augusto; GARCIA, Regina Leite (Org.). Currículo: pensar, sentir e diferir. Rio de Janeiro: DP\&A, 2004. p. 159-77.

FETZNER, Andréa Rosana; SOUZA, Maria Elena Viana. Concepções de conhecimento escolar: potencialidades do Programa Institucional de Bolsa de Iniciação à Docência. Educação e Pesquisa, São Paulo, v. 38, n. 3, p. 683-94, jul./set. 2012.

FREIRE, Paulo. Pedagogia do oprimido. Rio de Janeiro: Paz e Terra, 2011.

GARCIA, Regina Leite. Encontros e desencontros na escola: um currículo em movimento. In. FERRAÇO, Carlos E.; CARVALHO, Janete M. (Org.). Currículos, pesquisas, conhecimentos e produção de subjetividades. Petrópolis, RJ: Dp et Alii; Vitória, ES: Nupec/UFES, 2012. p. 105-18.

. Para quem investigamos - para quem escrevemos: reflexões sobre a responsabilidade social do pesquisador. In. GARCIA, Regina Leite (Org.). Para quem pesquisamos para quem escrevemos. São Paulo: Cortez, 2011. p.15-41.

GIROUX, Henry A. Os professores como intelectuais: rumo a uma pedagogia crítica da aprendizagem. Porto Alegre: Artes Médicas, 1997.

LIMA, Licínio C. Aprender para ganhar, conhecer para competir: sobre a subordinação da educação na "sociedade da aprendizagem". São Paulo: Cortez, 2012.

. A educação faz tudo? Crítica ao pedagogismo na "sociedade da aprendizagem". Revista Lusófona de Educação, v. 15, n. 15, p. 41-54, ago. 2010.

. Cidadania e educação: adaptação ao mercado competitivo ou participação na democratização da democracia? Educação, Sociedade \& Culturas, Porto, Portugal, n. 23, p. 71-90, 2005.

MOREIRA, Antonio Flávio. Qualidade na educação e no currículo: tensões e desafios. Trabalho apresentado em mesa-redonda do Seminário "Educação de qualidade: desafios atuais", promovido pela Novamerica, Centro Cultural Poveda e Colégio Teresiano, em 27 de setembro de 2008.

MOREIRA, Antonio Flávio; TADEU, Tomaz. Sociologia e teoria crítica do currículo: uma introdução. In: MOREIRA, Antonio Flávio; TADEU, Tomaz. (Org.). Currículo, cultura e sociedade. São Paulo: Cortez, 2011. p. 13-47.

PAVAN, Ruth. Diversidade cultural, desigualdade social e exclusão: um encontro com professores da educação básica. Trabalho apresentado no XVI ENDIPE- Encontro Nacional de Didática e Práticas de Ensino, UNICAMP, Campinas, SP, 2012.

. A reflexão dos professores e professoras da Educação de Jovens e Adultos sobre exclusão social. 2005. 330f. Tese (Doutorado em Educação) - Universidade do Vale do Rio dos Sinos (UNISINOS), São Leopoldo, RS, 2005. 
PINTO, Álvaro Vieira. Sete lições sobre educação de adultos. São Paulo: Cortez, 1984.

SAUL, Ana Maria. O pensamento de Paulo Freire na educação brasileira: análise de sistemas de ensino a partir de 1990. Currículo sem Fronteiras, v. 12, n. 3, p. 37-56, set./ dez. 2012.

SAWAIA, Bader. Introdução: exclusão ou inclusão perversa. In: SAWAIA, Bader (Org.). Artimanhas da exclusão: análise psicossocial e ética da desigualdade social. 9. ed. Petrópolis, RJ: Vozes, 2009. p. 7-13.

TORRES, Rosa María. A educação em função do desenvolvimento local e da aprendizagem. In: CENPEC-Centro de estudos e pesquisa em educação, cultura e ação comunitária (Org.). Muitos lugares para aprender. São Paulo: CENPEC, 2003. p. 81-9.

VEIGA-NETO, Alfredo. Cultura e currículo: um passo adiante. In: MOREIRA Antonio Flavio; PACHECO, José Augusto; GARCIA, Regina Leite (Org.). Currículo: pensar, sentir e diferir. Rio de Janeiro: DP\&A, 2004. p. 51-5.

. Pensar a escola como uma instituição que pelo menos garanta a manutenção das conquistas fundamentais da Modernidade. In: COSTA, Marisa Vorraber (Org.). A escola tem futuro? Entrevistas. Rio de Janeiro: DP\&A, 2003. p. 103-26.

\section{Sobre a autora:}

Ruth Pavan: Doutora e Mestre em Educação pela Universidade do Vale do Rio dos Sinos (UNISINOS) e Pós-Doutora pela UMINHO. Graduada em Pedagogia. É membro do quadro permanente de docentes do Programa de Pós-Graduação em Educação - Mestrado e Doutorado, da Universidade Católica Dom Bosco (UCDB), na Linha de Pesquisa Práticas Pedagógicas e suas Relações com a Formação Docente, exercendo atividades de pesquisa, orientação de mestrado e doutorado e ensino. Tem experiência na área da Educação, com ênfase em Formação de Professores, Currículo e Exclusão.E-mail: ruth@ucdb.br

\section{Recebido em dezembro de 2017. Aprovado em junho de 2018.}

